NIST Economic Analysis Briefs 1

\title{
The Economic Impact of Technology Infrastructure for Advanced Manufacturing: An Overview
}

\author{
Gary Anderson (gary.anderson@nist.gov) \\ Technology Partnerships Office, Innovation \& Industry Services
}

\section{Key Findings}

October 2016

- Conservative estimates indicate that meeting key technical needs would save over \$100 billion annually in emerging advanced manufacturing sectors in the US.

- Barriers to innovation increase the cost of advanced manufacturing R\&D, weaken private investment incentives, foster proprietary standards that can further distort the market and magnify the role of public research institutions.

- Important linkages across technical needs mean that closing select technical gaps - while leaving other needs unmet - would fail to allow domestic manufacturers to fully realize economic impact.

- Manufacturing research consortia and technology extension services are needed to meet critical technical needs and ensure that small and medium-sized enterprises benefit from advanced manufacturing technology.

\section{Introduction}

The National Institute of Standards and Technology (NIST) aims to develop the capabilities necessary to carry out its key role in the Nation's innovation ecosystem in part by fortifying U.S. advanced manufacturing capabilities. Because the Nation's long-term competitiveness relies on its global leadership in advanced manufacturing capabilities, NIST invests in the development and deployment of unique tools to support U.S. advanced manufacturing through both its intramural and extramural programs. NIST recently contracted a series of independent analyses ${ }^{1,2}$ to inform its investments. These studies identified a suite of technology infrastructure ${ }^{3}$ needs - needs for a broad base of public and quasi-public technologies and technical knowledge. The analysis addresses technical gaps in four key advanced manufacturing sectors: additive manufacturing; advanced robotics and automation; advanced roll-to-roll manufacturing; and smart manufacturing. Closing these gaps will support the research, development, production and diffusion activities of national laboratories, universities and firms alike. Conducting extensive original interviews and data collection, identifying the barriers to the adoption of advanced manufacturing technology and estimating the impact of eliminating these barriers is the unique contribution of this analysis.

Meeting the critical technology infrastructure needs across these sectors also delivers domestic manufacturers important new capabilities. For example, additive manufacturing (AM) technologies that make objects and parts by joining ultrathin layers of material layer-by-layer have "great potential to enable both sustaining and disruptive innovation." Next-generation advanced robots will be mobile, free to move about their environments and able to safely collaborate with humans. The studies find that advanced robotics and automation are potential game-changing technologies for strengthening the U.S. manufacturing sector, particularly for small and medium-sized manufacturers (SMEs). Similarly, advanced roll-to-roll (R2R) production methods offer the opportunity to merge the precision 
and uniformity of the microelectronics industry with the scale and cost structure of high-throughput industries such as optical films, printing and textiles. Smart manufacturing processes that use digital information to optimize product, factory and supply-chain operations have introduced a vast array of new opportunities for increasing efficiency, lowering costs, and improving quality throughout the advanced manufacturing sector.

However, the studies identify technology infrastructure needs - "currently unmet needs for measurement science, including metrology and test methods, traceable reference data, and other formal knowledge - that limit [advanced manufacturing] technology's further development and adoption, and the ways in which meeting these needs could spur innovation and growth in US advanced manufacturing." Each of the four studies identifies 5 to 10 critical needs. Individual studies and the associated NIST Economic Analysis Briefs provide details.

Table 1: Potential Annual Cost Savings

\begin{tabular}{|l|c|c|}
\hline & Annual Cost Saving (\$Billions) & Percentage Cost Reduction \\
\hline Additive Manufacturing & $\$ 4.1$ & $18.3 \%$ \\
\hline $\begin{array}{l}\text { Advanced Robotics and } \\
\text { Automation }\end{array}$ & $\$ 40.1$ & $5.3 \%$ \\
\hline Roll-to-Roll Manufacturing & $\$ 0.4$ & $14.7 \%$ \\
\hline Smart Manufacturing & $\$ 57.4$ & $3.2 \%$ \\
\hline
\end{tabular}

\section{Findings}

The analyses provide conservative estimates which indicate that meeting key technical needs would save over $\$ 100$ billion annually in emerging advanced manufacturing sectors. Both the total annual cost savings and the rate of cost reduction vary across the sectors studied. Meeting the technical needs in advanced roll-to-roll and additive manufacturing would lower costs by $15 \%$ and $18 \%$ respectively. Importantly, the estimated benefits are only those directly attributable to closing the identified technical gaps rather than the overall benefit of advanced manufacturing technology. The studies identify the potential systematic application of robotics and automation as well as smart manufacturing throughout the manufacturing sector, which naturally raises the total impact estimates relative to technologies with more narrow applicability such as additive and advanced R2R. The conservative estimation approach, which is based on current levels of adoption, further lowers estimated benefits. Overall, the impact estimates are particularly impressive since they do not include benefits that interviewees could not rigorously quantify such as R\&D cost savings, transactions cost savings, benefits of new and improved products, long term growth and competitiveness benefits of advanced manufacturing or other societal benefits.

The studies identify certain barriers to innovation, caused by market failures, that increase the cost of advanced manufacturing $R \& D$, weaken private investment incentives and foster proprietary standards that can further distort the market. The stakeholder interviews identify critical uncertainties that increase transactions and adoption costs and diminish the incentive of all parties - across entire supply chains - to invest in advanced manufacturing technology. Further, the studies provide evidence that proprietary standards ${ }^{4}$ fail to address the underlying barriers to innovation. The analysis demonstrates 
that when measurement and test methods, interoperability standards, scientific and engineering databases are treated as proprietary intellectual assets, firms can use these to create market distortions by conveying market power through branding and reputation. Only by meeting needs for trusted third-party standards and performance data will adopters "know what they are buying at various cost points," be confident in the performance of innovative materials, products and technologies, and fully compensate developers for their research investments. The studies consistently point to the trusted "honest broker" role often played by public institutions as vital to overcoming such barriers to innovation. These findings highlight the importance of public research institutions in meeting the identified technical needs.

Important linkages across technical needs exist and must be recognized. This increases the importance of ensuring needs are met across all categories. For example, high-fidelity computer modeling and simulation require advances in measurement science to produce new scientific and engineering databases. Consequently, "unbalanced" investment - closing select technical gaps while leaving other needs unmet - would likely limit US ability to "fully realize economic impact."

Manufacturing research consortia and technology extension services are needed to meet critical technical needs and ensure small and medium-sized enterprises benefit from advanced manufacturing technology. For example, the studies show that the needs of small and medium manufacturing establishments are particularly acute. Small manufacturers noted that they "do not have the adequate resources to exhaustively test and validate." In this environment, trusted and publicly available data "could accelerate the introduction of [advanced manufacturing] in existing industries, as well as new industries, and open up additional opportunities for small suppliers and manufacturers." Additionally, the studies identified needs for certain pre-competitive technology platforms. The analysis concludes that consortia are an import tool for developing critical technology platforms that meet industry specifications. Consortia can also address critical interoperability issues and "bring the multidisciplinary teams together to solve the analysis problems that would advance smart manufacturing." Consortia and public private partnerships aid the implementation of new technology, which can be "as much an organizational and cultural challenge as it is a technical challenge." These partnerships and extension services "could also help connect users with developers of advanced manufacturing technologies by creating platforms" to transfer and disseminate technology. The study identifies potential new business models and public-private partnerships as a potential route to overcome these barriers.

\section{References}

[1] Anderson G (2013) The Impact of Federally Performed R\&D: Twenty Years of Economic Analysis at the National Institute of Standards and Technology. 2013 Technology Transfer Society Conference.

[2] Anderson G (2016) The Economic Impact of Technology Infrastructure for Advanced Robotics. (NIST, Gaithersburg, MD) NIST Economic Analysis Briefs 2.

[3] Anderson G (2016) The Economic Impact of Technology Infrastructure for Additive Manufacturing. (NIST, Gaithersburg, MD) NIST Economic Analysis Briefs 3.

[4] Anderson G (2016). The Economic Impact of Technology Infrastructure for Smart Manufacturing. (NIST, Gaithersburg, MD) NIST Economic Analysis Briefs 4.

[5] Anderson G (2016) The Economic Impact of Technology Infrastructure for Advanced Roll-to-Roll Manufacturing. (NIST, Gaithersburg, MD) NIST Economic Analysis Briefs 5. 
[6] Gallaher MP, Oliver ZT, Reith KT and O'Connor AC (2016) Economic Analysis of Technology Infrastructure Needs for Advanced Manufacturing: Smart Manufacturing. (NIST, Gaithersburg, MD) NIST GCR 16-007.

[7] Link A Scott J (2011) The theory and practice of public-sector R\&D economic impact analysis. (NIST, Gaithersburg, MD) Planning Report 11-1. https://www.nist.gov/sites/default/files/documents/director/planning/report11-1.pdf.

[8] Link, AN, Oliver ZT, O'Connor AC (2016). Economic Analysis of Technology Infrastructure Needs for Advanced Manufacturing: Advanced Robotics and Automation. (NIST, Gaithersburg, MD) NIST GCR 16-005.

[9] O'Connor AC, Beaulieu TJ Rothrock GD (2016). Economic Analysis of Technology Infrastructure Needs for Roll-to-Roll Manufacturing. (NIST, Gaithersburg, MD) NIST GCR 16-008.

[10] Scott TJ, Beaulieu TJ, Rothrock GD, O'Connor AC (2016). Economic Analysis of Technology Infrastructure Needs for Advanced Manufacturing: Additive Manufacturing. (NIST, Gaithersburg, MD) NIST GCR 16-006.

[11] Tassey G (2007) The Technology Imperative. (Edward Elgar, Cheltenham).

[12] Tassey G (2015) The Economic Nature of Knowledge Embodied in Standards for TechnologyBased Industries. Routledge Handbook of the Economics of Knowledge, eds Antonelli C, Link A (Routledge, New York), pp. 189-207.

\footnotetext{
${ }^{1}$ See Gallaher et al. [6], Link et al. [8] O'Connor et al. [9] and Scott et al. [10].

${ }^{2}$ See Anderson [2], [3], [4] and [5] for findings and overviews of individual studies.

${ }^{3}$ Technology infrastructure includes infratechnologies and technology platforms. Infratechnologies are technical tools, such as measurement and test methods, reference materials, scientific and engineering databases, process models, and the technical basis for physical and functional interfaces between individual components of both cyber and physical systems technologies. Technology platforms are precompetitive proofs of concept that demonstrate the potential commercial viability of multiple new or improved products, processes, or services. Technology infrastructure shares many common features with tangible infrastructure. Namely, it is difficult and even undesirable to exclude potential users and usage of the technology infrastructure by a particular organization does not does not preclude others from benefiting to much the same extent. See Anderson [1], Link and Scott [7] and Tassey [11] for a richer discussion of the public good nature of technology infrastructure.

${ }^{4}$ Proprietary standards can include both product and non-product standards such as measurement and test methods, interoperability standards, scientific and engineering databases and artifacts such as reference materials (infratechnologies). At times, these non-product standards become the technical basis for standards developed through voluntary consensus standards developing organizations. However, just as market dynamics drive the adoption of de facto product standards so to can market dynamics drive the development and adoption of non-products standards. Tassey [12] notes the negative effects on economic efficiency of market power conveyed through proprietary product and non-product standards.
} 